\title{
Quasi-static and high strain rate properties of a cross-ply metal matrix composite
}

\author{
I.W. Hall ${ }^{\mathrm{a}, *}$, A. Tasdemirci ${ }^{\mathrm{b}}$, J. Derrick ${ }^{\mathrm{a}}$ \\ a Department of Mechanical Engineering, University of Delaware, Newark, DE 19716, USA \\ ${ }^{\mathrm{b}}$ Department of Mechanical Engineering, Izmir Institute of Technology, Izmir, Turkey
}

\section{A R T I C L E I N F O}

\section{Article history:}

Received 1 October 2008

Received in revised form

24 November 2008

Accepted 11 December 2008

\section{Keywords:}

Metal matrix composite

High strain rate

Compression

Cross-ply

\begin{abstract}
A B S T R A C T
A series of compression tests has been carried out at quasi-static and high strain rates on cylindrical samples of an alumina fiber/Al-6061 metal matrix composite. The composite plates were prepared with fibers in the $0^{\circ}, 0 / 90^{\circ}$ and $\pm 45^{\circ}$ orientations. It was found that the mechanical properties were strongly dependent upon the imposed strain rate, with fracture stress increases of $>50 \%$ being noted for several orientations at high strain rates: these increases are not believed to be related to strain rate sensitivity of either the matrix or fibers but to arise from the inertia of fragments which remain in place after fracture and continue to bear load. Also, and in contradiction to behavior anticipated from the rule of mixtures, it was found that $0 / 90^{\circ}$ samples exhibited properties superior to those of $0^{\circ}$ unidirectional samples. Highspeed photography was used to confirm the sequence of deformation and fracture events at high strain rate.
\end{abstract}

(ㄷ) 2008 Elsevier B.V. All rights reserved.

\section{Introduction}

Metal matrix composites (MMCs) have been under development for many years based upon their promise of higher specific properties, such as strength, stiffness and wear resistance. Once their quasi-static properties had begun to be satisfactorily understood, attention was next focussed on their dynamic or high strain rate properties and considerable research has already been carried out to characterize the high strain rate response of particulate and discontinuous fiber reinforced composites, both experimentally and numerically.

However, considerably less research has been devoted to long, continuous fiber reinforced MMCs and, within this group of materials, most of the research has concentrated on unidirectionally reinforced MMCs tested in either the longitudinal or transverse directions [1-5]. Cady and Gray [3] reported such results on a $50 V_{f} \%$ $\mathrm{Al}_{2} \mathrm{O}_{3}$ fiber reinforced $\mathrm{Al}-6061$ alloy and noted no strain rate dependency in the longitudinal direction but a substantial dependency in the transverse direction which was attributed to the effect of the aluminum matrix. Extensive buckling and kinking was noted in the longitudinal direction.

Several recent studies have been carried out on various aspects of the mechanical behavior of Nextel $610^{\mathrm{TM}}\left(\mathrm{Al}_{2} \mathrm{O}_{3}\right)$ fibers and MMCs based on these fibers [6-11]. It was found that the tensile strength of MMCs was very dependent upon the fiber-matrix interfacial bond strength and the compressive strength was strongly

\footnotetext{
* Corresponding author. Tel.: +1 302831 1295; fax: +1 3028313619.

E-mail address: halliw@udel.edu (I.W. Hall).
}

dependent on the shear strength of the matrix [10]. One of the few reported investigations of cross-ply lay-ups was by Lee et al. who studied a carbon fiber reinforced 7075-Al alloy [12]: they reported a strong dependence of flow stress on strain rate (at rates above $10^{3} \mathrm{~s}^{-1}$ ) and test temperature.

Another important aspect of this field is that the vast majority of all research on the dynamic properties of MMCs has addressed their behavior under compression. While that may not pose a significant limitation or concern for particulate or discontinuously reinforced MMCs, the same is not the case for continuously reinforced MMCs where pure compressive failure is notoriously difficult to achieve without premature buckling or brooming. Even the basic geometry of compression test samples is under discussion. For example, Roebuck et al. [13] investigated, and made recommendations concerning, the dimensions of cylindrical samples; Anthoine et al. [14] studied long flat coupons and stated that loading must be achieved by a combination of end-loading and shear-loading through end-tabs. Cady and Gray [3] used several types of samples, including one with a reduced section gage length and one that used end-constraint, and noted that end constraint gave maximum stress values that were $\sim 600 \mathrm{MPa}$ higher than for the other samples. Even the compression testing of more conventional polymer matrix composites is still under vigorous discussion $[15,16]$. Consequently, it is to be noted at the outset that it is not claimed that the strength values in the present report correspond to pure compressive failure. Nevertheless, as a basis for internal comparison and future development, it is believed that the relative values are meaningful and a parallel program of research is underway in this laboratory to establish accurate values for these quantities. 
Table 1

Compression test data.

\begin{tabular}{|c|c|c|c|c|c|}
\hline Sample & Strain rate & & Longitudinal & Long transverse & Short transverse \\
\hline \multirow{6}{*}{$0^{\circ}$} & & $\sigma_{\mathrm{y}}(\mathrm{MPa})$ & & $285 \pm 41$ & $367 \pm 24$ \\
\hline & Quasi-static & $\sigma_{\max }(\mathrm{MPa})$ & $1603 \pm 36$ & $398 \pm 12.6$ & $473 \pm 28$ \\
\hline & & Elongn. & $6.3 \pm 2.6 \%$ & $4.5 \pm 0.6 \%$ & $4.0 \pm 0.4 \%$ \\
\hline & & $\sigma_{\mathrm{y}}(\mathrm{MPa})$ & & $561 \pm 21$ & $529 \pm 50$ \\
\hline & High strain rate & $\sigma_{\max }(\mathrm{MPa})$ & $2460 \pm 112$ & $600 \pm 12$ & $593 \pm 24$ \\
\hline & & Elongn. & $2.2 \pm 0.7 \%$ & $3.7 \pm 0.9 \%$ & $1.3 \pm 0.8 \%$ \\
\hline \multirow{6}{*}{$0 / 90^{\circ}$} & & $\sigma_{\mathrm{y}}(\mathrm{MPa})$ & & & \\
\hline & Quasi-static & $\sigma_{\max }(\mathrm{MPa})$ & $1919 \pm 204$ & $1921 \pm 156$ & $969 \pm 33$ \\
\hline & & Elongn. & $6.1 \pm 0.3 \%$ & $6.9 \pm 0.5 \%$ & $6.7 \pm 0.3 \%$ \\
\hline & & $\sigma_{\mathrm{y}}(\mathrm{MPa})$ & & & \\
\hline & High strain rate & $\sigma_{\max }(\mathrm{MPa})$ & $2859 \pm 163$ & $2591 \pm 113$ & $1065 \pm 20$ \\
\hline & & Elongn. & $3.5 \pm 0.4 \%$ & $5.0 \pm 2.8 \%$ & $2.4 \pm 0.2 \%$ \\
\hline \multirow{6}{*}{ $\pm 45^{\circ}$} & & $\sigma_{\mathrm{y}}(\mathrm{MPa})$ & $400 \pm 32.5$ & $367 \pm 25$ & \\
\hline & Quasi-static & $\sigma_{\max }(\mathrm{MPa})$ & $587 \pm 17.3$ & $597 \pm 56$ & $980 \pm 67$ \\
\hline & & Elongn. & $28.3 \pm 4.8 \%$ & $28.4 \pm 7.9 \%$ & $6.0 \pm 0.3 \%$ \\
\hline & & $\sigma_{\mathrm{y}}(\mathrm{MPa})$ & $467 \pm 6.6$ & $457 \pm 23$ & \\
\hline & High strain rate & $\sigma_{\max }(\mathrm{MPa})$ & $629 \pm 4$ & $744 \pm 28$ & $1149 \pm 92$ \\
\hline & & Elongn. & $18.2 \pm 2.1 \%$ & $16 \pm 2.9 \%$ & $2.0 \pm 0.8 \%$ \\
\hline
\end{tabular}

\section{Experimental}

The MMCs used in the present study consisted of Nextel $610^{\mathrm{TM}}$ fibers in a matrix of $\mathrm{Al} \mathrm{6061,} \mathrm{heat-treated} \mathrm{to} \mathrm{the} \mathrm{T6} \mathrm{condition.} \mathrm{The}$ nominal volume fraction of fibers was $65 \%$ and the composites were prepared as $152.5 \mathrm{~mm} \times 76.2 \mathrm{~mm} \times 12.7 \mathrm{~mm}$ plates. Three different lay-ups were produced, namely unidirectionally reinforced $0^{\circ}$ plates (all fibers in the long direction), and uniform cross-ply plates with $0 / 90^{\circ}$ and $\pm 45^{\circ}$ lay-ups. Preforms were made by preparing individual layers of aligned fibers with a fugitive binder, laying them up in a mold in the desired sequence, then burning off the binder. The molten alloy was then introduced under pressure into the preforms. Finally, the plate surfaces were diamond machined top and bottom to the final uniform thickness.

Quasi-static and high strain rate compression tests were performed on cylindrical samples prepared by core drilling slices cut from the appropriate orientation. The samples were typically $10 \mathrm{~mm}$ in diameter and $10.4-12.7 \mathrm{~mm}$ in height although slightly smaller diameter samples had to be used for some of the higher strength orientations. Particular attention was paid to ensure that the cylindrical samples had highly polished, flat, parallel endsurfaces. Samples were prepared in three orientations from each plate, namely, with the cylinder axis parallel to the long dimension of the plate (longitudinal, L, orientation), parallel to the width of the plate (long transverse, LT, orientation) and through the thickness of the plate (short transverse, ST, orientation). It is pointed out here that, for a composite in which long, continuous, fibers are uniformly distributed in the matrix, several pairs of orientations should be equivalent: specifically, the $0 / 90^{\circ} \mathrm{L}$ and $0 / 90^{\circ} \mathrm{LT}$ samples should resemble each other, as should the $0^{\circ} \mathrm{LT}$ and $0^{\circ}$ ST pair, the $\pm 45^{\circ} \mathrm{L}$ and $\pm 45^{\circ}$ LT pair, and the $0 / 90^{\circ}$ ST and $\pm 45^{\circ}$ ST pair. $0^{\circ}$ LT and $0^{\circ}$ ST samples could, of course, both be alternatively described as $90^{\circ}$ samples but the present nomenclature is preferred as it preserves the details of the processing history.

Quasi-statically tested samples were tested at an initial strain rate of $\sim 4 \times 10^{-4} \mathrm{~s}^{-1}$. WC anvils were used both to protect the platens of the testing machine and to ensure accurate strain measurements: selected samples were strain gauged for Young's modulus determinations. Samples were tested at high strain rate using a split Hopkinson pressure bar apparatus equipped with Inconel 718 incident, transmitter, and striker bars which were $3570 \mathrm{~mm}, 1785 \mathrm{~mm}$, and $360 \mathrm{~mm}$ in length respectively. The ends of the bars were protected from indentation by the use of impedance matched high strength maraging steel end-caps which were replaced with newly machined ones for each test. Tests were all performed with a striker bar velocity of approximately $20 \mathrm{~m} / \mathrm{s}$, producing a nominal initial strain rate of $\sim 800-1000 \mathrm{~s}^{-1}$ in a $10.4 \mathrm{~mm}$ long cylindrical sample. At least six samples were tested in each
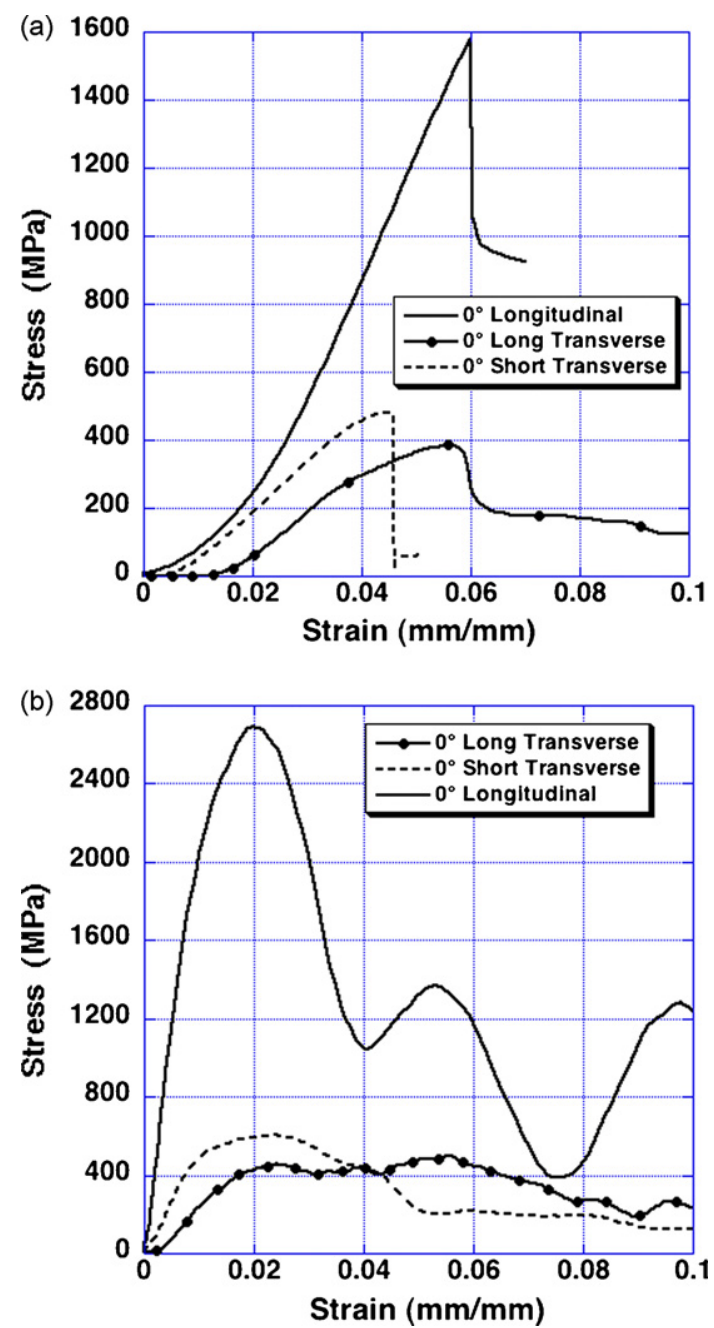

Fig. 1. Typical stress $v s$. strain curves for the three orientations of unidirectional $\left(0^{\circ}\right)$ samples: (a) quasi-static; (b) high strain rate. 
orientation and at each of the strain rates investigated. The values reported below were obtained from the conventional one-wave treatment but the two-wave data reduction approach was applied to many samples in order to confirm that they were indeed being subjected to a uniform stress state before fracture began. Additionally, pulse shapers were used with most samples since the anticipated failure strains were relatively low.

High-speed photography was used to record the macroscopic details of the fracture process. After testing, cross-sections of selected samples were prepared for optical microscopy and fracture surfaces from other samples were examined by scanning electron microscopy in order to determine the microscopic events accompanying deformation and fracture.

\section{Results}

\subsection{Mechanical testing}

The results of mechanical testing are presented together below in Table 1 and will be considered separately in greater detail. In many cases the samples underwent only elastic deformation before fracture and $\sigma_{\max }$ values are reported in these cases: in other cases samples exhibited marked deviations from linear elastic behavior indicating the onset of extensive plastic deformation. The stresses at which significant deviations began are reported as $\sigma_{\mathrm{y}}$ values and
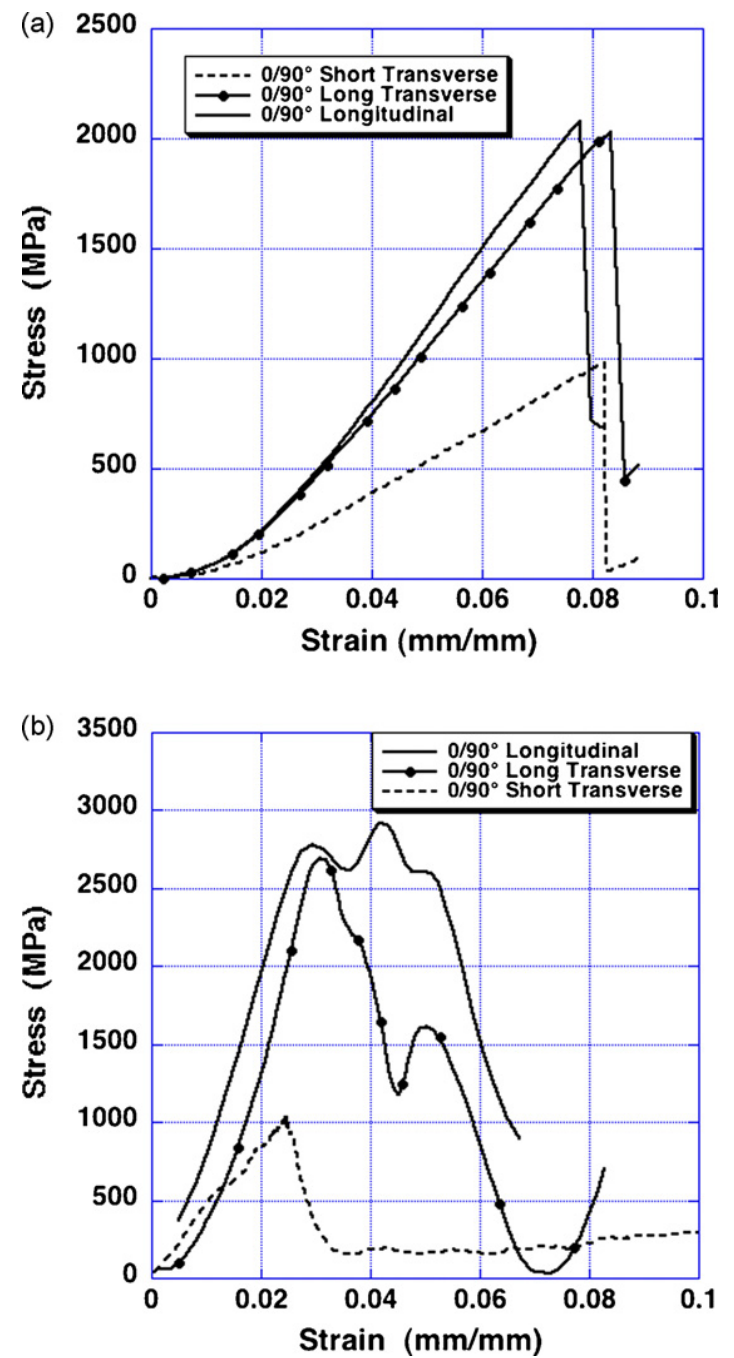

Fig. 2. Typical stress $v s$. strain curves for the three orientations of $0 / 90^{\circ}$ samples: (a) quasi-static; (b) high strain rate. correspond approximately, for quasi-static tests at least, to a yield strength.

\subsection{1. $0^{\circ}$ Samples}

Samples tested quasi-statically in the longitudinal direction exhibited constantly increasing elastic loading right up to the instant of fracture at a strain of $\sim 6.3 \%$. Fracture occurred by apparently simultaneous kinking and longitudinal splitting at one end of the sample. Typical examples of this and the following two stress/strain curves are presented in Fig. 1(a).

Samples tested quasi-statically in the LT direction exhibited a clear bilinear stress/strain curve with a pronounced knee at $\sim 250 \mathrm{MPa}$ corresponding to yielding of the Al-6061 matrix. On continued loading, samples showed pronounced plasticity and underwent a further approximately $1.9 \%$ strain before catastrophic failure.

Quasi-statically tested ST samples, however, exhibited a more uniform elastic region which finally deviated from linearity at $\sim 367 \mathrm{MPa}$ and was followed by fracture at $\sim 473 \mathrm{MPa}$. It is noteworthy that, although these two testing directions are nominally the same, the mechanical properties differed significantly and consistently between the two: this point will be discussed further below.
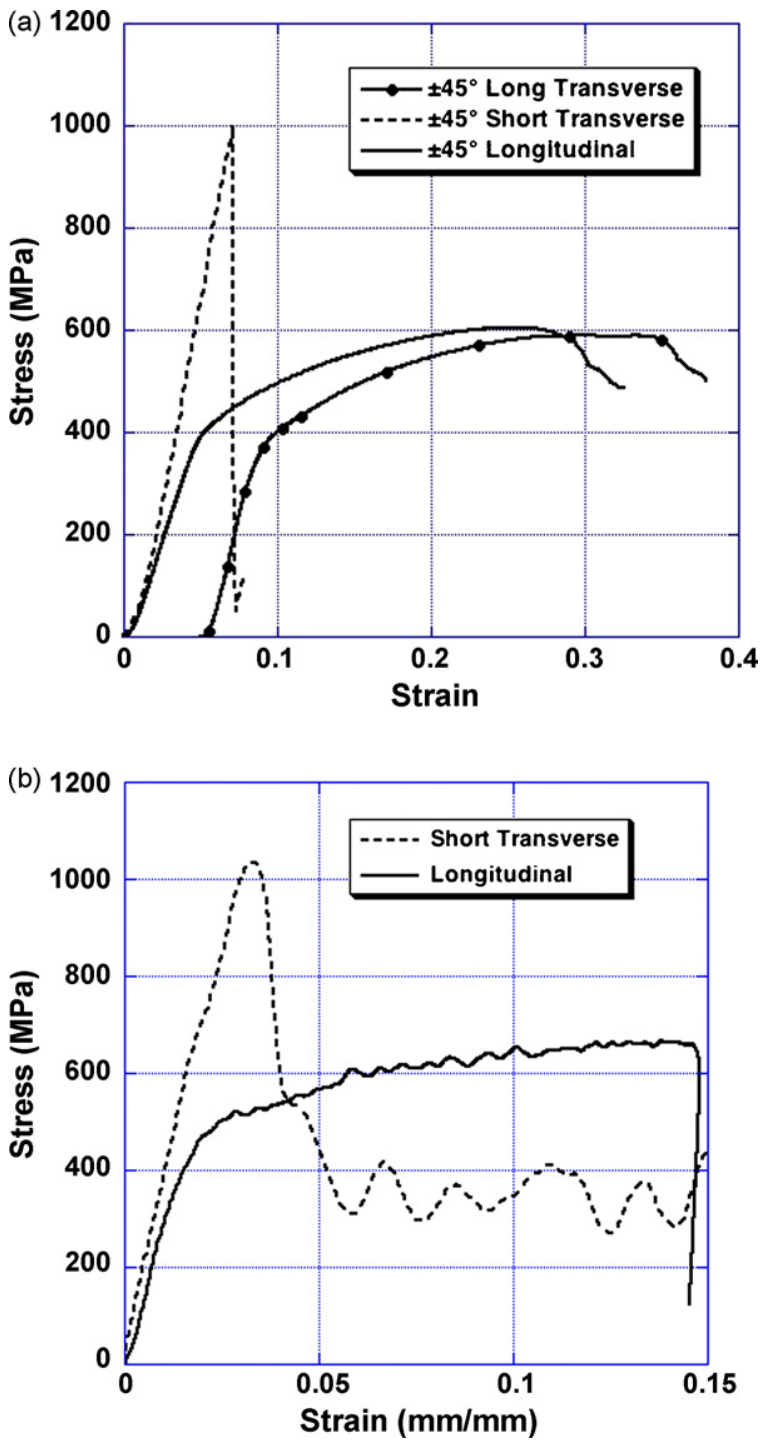

Fig. 3. Typical stress $v s$. strain curves for different orientations of $\pm 45^{\circ}$ samples: (a) quasi-static (LT data shifted laterally for clarity); (b) high strain rate. 
When tested at high strain rate the measured strength values were significantly higher in all three orientations, but particularly so in the longitudinal direction where an increase of $>800 \mathrm{MPa}$ was recorded. It is also noted that the strain to failure was generally reduced. Fig. 1(b) shows typical behavior of SHPB samples and it is seen that successive diminishing peaks are often observed. This gives an insight into the failure mechanism and indicates that the sample reached its maximum load and began to fail, for example by longitudinal splitting, but that the fragments remained substantially in place and were capable of being subsequently reloaded to some extent. (These reloading events occurred within the time window of the initial loading pulse and do not correspond to reloading due to subsequent reflections from the bar ends.)

\subsection{2. $0 / 90^{\circ}$ Samples}

Looking first at the quasi-static data, Fig. 2(a), as anticipated, both L and LT samples showed basically similar stress/strain records which were essentially linear until failure although some LT samples exhibited a slight reduction in gradient above $\sim 1500 \mathrm{MPa}$. The most striking observation, however, was that failure occurred close to $2000 \mathrm{MPa}$, i.e. a significantly higher stress than obtained for the $0^{\circ} \mathrm{L}$ samples despite the fact that only one half of the volume fraction of fibers was aligned along the test direction. ST samples failed at $\sim 970 \mathrm{MPa}$ and, again, all the stress/strain curves were strictly linear to failure.
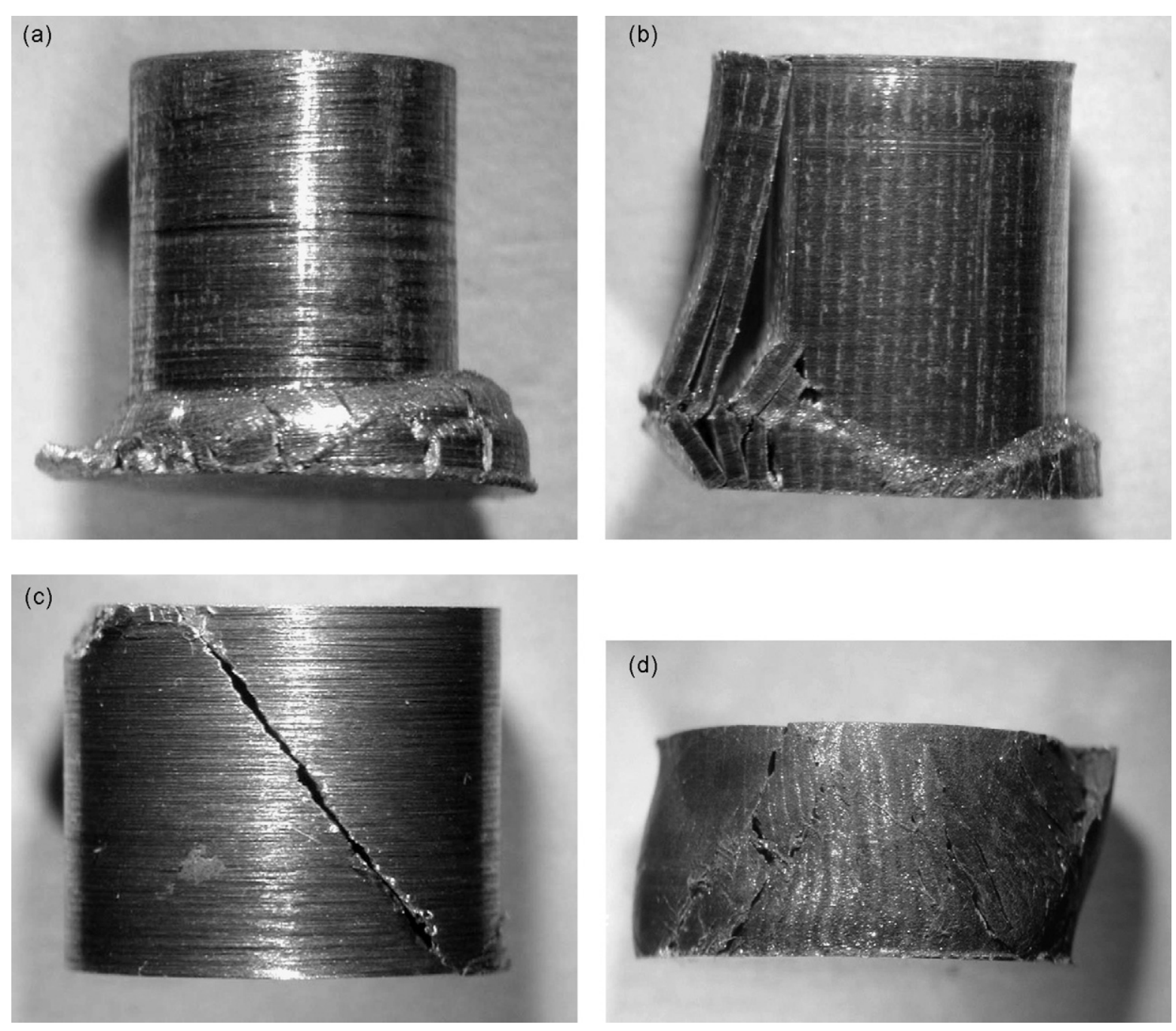

Table 2

Young's modulus as a function of sample orientation and ply lay-up.

\begin{tabular}{ll}
\hline Sample orientation & Young's modulus (GPa) \\
\hline $0^{\circ}$ Longitudinal & $298 \pm 11.5$ \\
$0^{\circ}$ Long. transverse & $177 \pm 20$ \\
$0 / 90^{\circ}$ Longitudinal & $225 \pm 16.3$ \\
$\pm 45^{\circ}$ Longitudinal & $210 \pm 25$ \\
\hline
\end{tabular}

For high strain rate samples, Fig. 2(b), the stress-strain records were essentially linear to failure and the measured strength values were, again, greater than those measured quasi-statically. Note that, although the values of the L and LT orientations apparently differ by $>250 \mathrm{MPa}$, the values lie close (within \pm 1 standard deviation of each other). ST samples yielded $\sigma_{\max }$ values of $1065 \mathrm{MPa}$, significantly in excess of the corresponding quasi-static data and almost twice the level of any $0^{\circ}$ ST samples.

\subsection{3. $\pm 45^{\circ}$ Samples}

As expected, quasi-statically tested $\pm 45^{\circ}$ samples of L and LT orientations, Fig. 3(a), showed identical behaviors with a pronounced yield point at $\sim 400 \mathrm{MPa}$ and a maximum stress of $\sim 590 \mathrm{MPa}$. The strain to maximum load was $\sim 28 \%$. ST samples exhibited linear stress/strain curves up to failure at $\sim 980 \mathrm{MPa}$ and were substantially consistent with data from $0 / 90^{\circ}$ ST samples.

Fig. 4. Quasi-statically tested samples: (a) $0^{\circ}$ L; (b) $0 / 90^{\circ}$ LT; (c) $\pm 45^{\circ} \mathrm{ST}$; (d) $\pm 45^{\circ}$ L. 
Compared with quasi-static data, samples tested at high strain rate, Fig. 3(b), showed generally higher yield and maximum stresses in all orientations. Measured $\sigma_{\mathrm{y}}$ values for L and LT samples were essentially identical whereas $\sigma_{\max }$ values varied somewhat since they depended on the extent of deformation before failure, i.e. on the strain at which fracture was initiated. The strains to failure were, however, approximately halved in each case relative to the quasistatic values. Again as expected, the ST values were quite consistent with those for the $0 / 90^{\circ}$ ST samples.

\subsubsection{Young's modulus}

Determination of reproducible Young's modulus values proved extremely difficult for the small cylindrical samples. A major cause of the difficulty was associated with placement of strain gages for which the spacing of their wire-threads was smaller than the dimensions of individual plies. As a consequence, any difference of strains between plies could lead to questionable values. Also, the fine diameter of the fibers and their small but non-negligible deviations from perfect alignment led to early non-linearity of the stress $v s$. strain curves which is not necessarily detectable on the scale of figures such as Figs. 1 and 2 but which becomes evident when strain gages are used.

Consequently, compression samples in the form of coupons $152 \mathrm{~mm} \times 12.8 \mathrm{~mm}$ were prepared from separately produced $2.6 \mathrm{~mm}$ thick plates that were nominally identical in composition and fiber $V_{\mathrm{f}}$. These were tested in a CLC fixture according to ASTM D 6641 and gave rather more consistent results that are tabulated below as Table 2 . The rule of mixtures modulus value for $0^{\circ}$ samples longitudinally reinforced with $65 \mathrm{~V}_{\mathrm{f}} \%$ Nextel 610 fibers is $\sim 271 \mathrm{GPa}$ based on reported tensile modulus values of $380 \mathrm{GPa}$ and $68 \mathrm{GPa}$ for the fibers and matrix, respectively. Since the modulus values were in excess of anticipated values, quantitative metallography was used to check the actual volume fraction of fibers. The actual volume fraction varied between $72 \%$ and $81 \%$ indicating that substantial compaction had occurred during the infiltration and consolidation stages. It should be noted that a packing density of this magnitude is only possible because the fibers are not circular in cross section but are instead "peanut" shaped as clearly illustrated in Fig. 10(b).

Similar local variations in fiber $\mathrm{V}_{\mathrm{f}}$ also contribute to the uncertainty in Young's modulus values calculated from the smaller cylindrical samples. Nevertheless, it was noted that the $0^{\circ}$ L samples consistently yielded values greatly in excess of the rule of mixtures and two samples even yielded values of $400 \mathrm{GPa}$ and $389 \mathrm{GPa}$, i.e. greater than the reported tensile modulus of the fibers themselves. Further work is underway to characterize the modulus of these materials.

\subsection{Microscopy}

\subsubsection{Macroscopic observations}

Fig. 4(a)-(d) present macro-photographs of selected samples after quasi-static testing. $0^{\circ} \mathrm{L}$ samples showed gradual but quite symmetrical brooming at one end, Fig. 4(a): the $0^{\circ}$ LT and ST samples showed simple shear failure at $45^{\circ}$ to the compression axis. $0 / 90^{\circ}$ $\mathrm{L}$ and LT specimens showed brooming that was less symmetrical than the $0^{\circ} \mathrm{L}$ samples but also showed a tendency to longitudinal splitting, Fig. 4(b). Both $0 / 90^{\circ}$ and $\pm 45^{\circ}$ ST specimens showed shear failure along a plane inclined at $\sim 55^{\circ}$ to the compression axis, Fig. 4(c). $\pm 45^{\circ}$ L and LT samples exhibited extensive deformation with failure finally occurring by a mixture of separation between ply boundaries and shear on planes inclined steeply with respect to the compression axis, Fig. 4(d).

When tested at high strain rate, however, some of the fracture sequences were somewhat different. For example, $0^{\circ} \mathrm{L}$ samples again showed extensive brooming but this was frequently observed to occur at both ends rather than only at one end as was the case
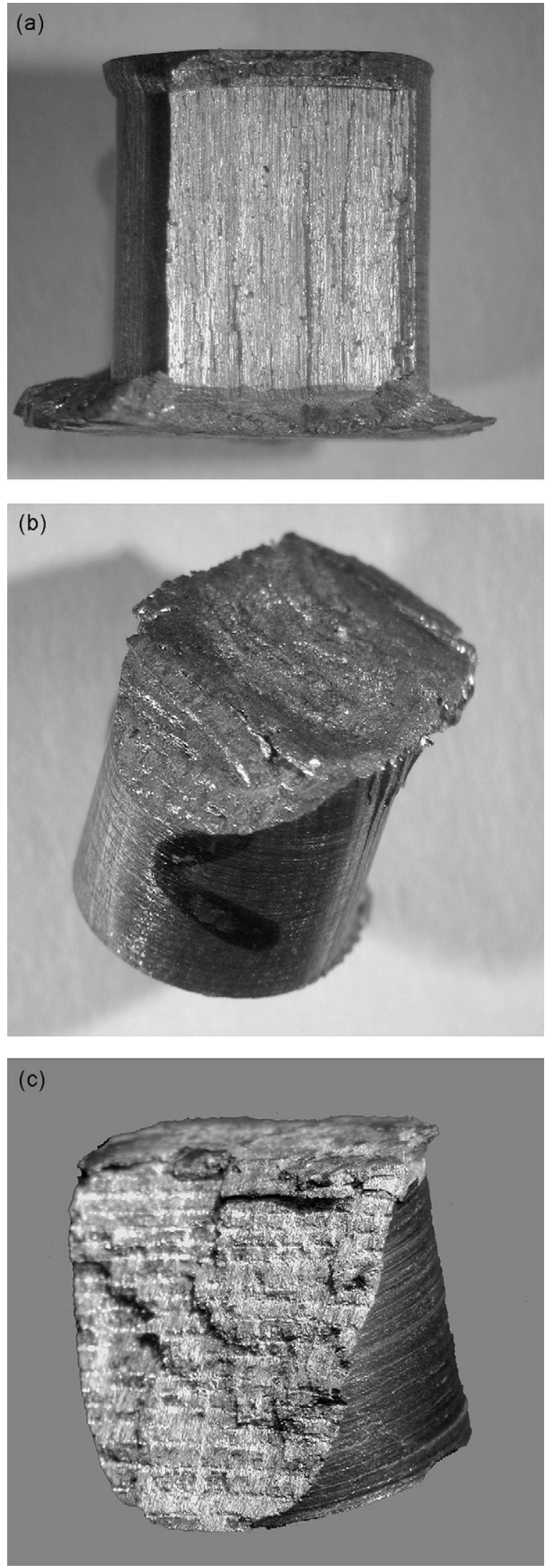

Fig. 5. (a) $0^{\circ} \mathrm{L}$ sample tested at high strain rate showing brooming at both ends which preceded longitudinal splitting. (b) $0 / 90^{\circ}$ LT sample tested at high strain rate showing a combination of brooming and shear across the layers. (c) $\pm 45^{\circ}$ ST sample tested at high strain rate showing shear across a steeply inclined, jagged plane. 
for quasi-static testing. Furthermore, brooming was often accompanied by longitudinal splitting as shown in Fig. 5(a). $0^{\circ}$ LT and ST samples showed complex shear processes which typically included shear along one major plane plus several parallel shears along adjacent diagonal planes.

$0 / 90^{\circ} \mathrm{L}$ and LT high strain rate samples all showed end brooming plus splitting diagonally across the layers close to the region of brooming, Fig. 5(b). 0/90 ST and $\pm 45^{\circ}$ ST samples all showed shear along a single plane at $\sim 30^{\circ}$ to the testing axis, Fig. 5(c).

Additional features of the deformation were also observed by high-speed photography of the experiments. For example, $0^{\circ} \mathrm{L}$ samples were seen to undergo extensive brooming and fragmentation before longitudinal splitting occurred, Fig. 6(a). Also, observation of 0/90 LT samples showed that brooming and shear at $\sim 45^{\circ}$ usually preceded the longitudinal splitting, Fig. 6(b). In addition, it was found that $\pm 45^{\circ} \mathrm{L}$ and LT specimens showed pronounced barreling of the cylinders before shear cracking at $45^{\circ}$ finally began to appear after a strain of $\sim 25 \%$ as shown in the high-speed photographic sequence in Fig. 6(c).

\subsubsection{Microscopic observations}

Microscopic examination confirmed the macroscopic observations above but also revealed several further features. For example, Fig. 7(a) shows a section through a quasi-statically tested $0^{\circ}$ LT sample in which the individual precursor layers of fibers may still be clearly discerned through the presence of lighter, matrix-rich regions. The presence of such regions of lower fiber volume fraction may be expected to influence the deformation and fracture properties. In this figure, the layers at the left have undergone extensive rotation during testing. It may be noted here also that the fibers are not circular but rather are 'peanut'shaped.

Fig. 7(b) is a section through the thickness close to the base of a $0 / 90^{\circ}$ LT specimen tested quasi-statically and shows typical kink band formation in the longitudinal fiber layers: this figure also illustrates the typical lay-up and ply thickness of the samples. Fig. 7(c) shows a view of a $0^{\circ} \mathrm{L}$ sample tested at high strain rate and clearly shows the severe fragmentation that accompanies intense kink band formation. (a)

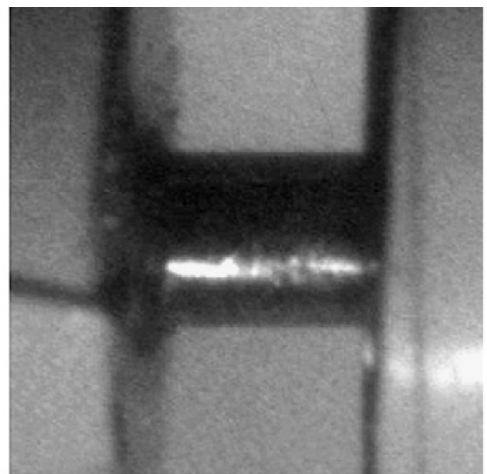

(b)

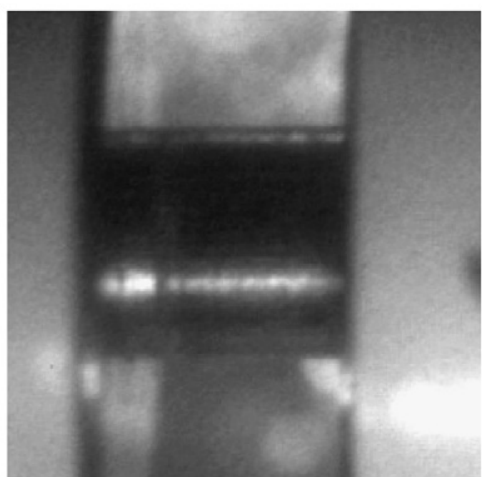

(c)

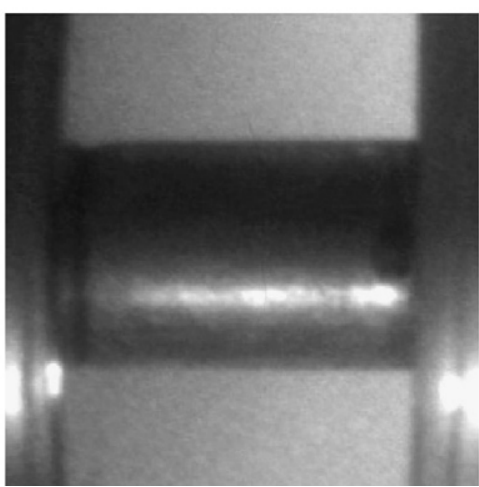

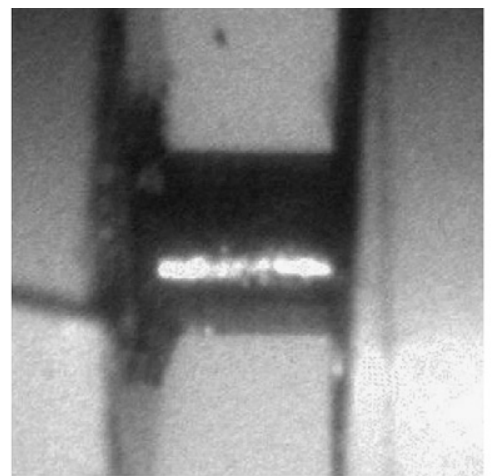
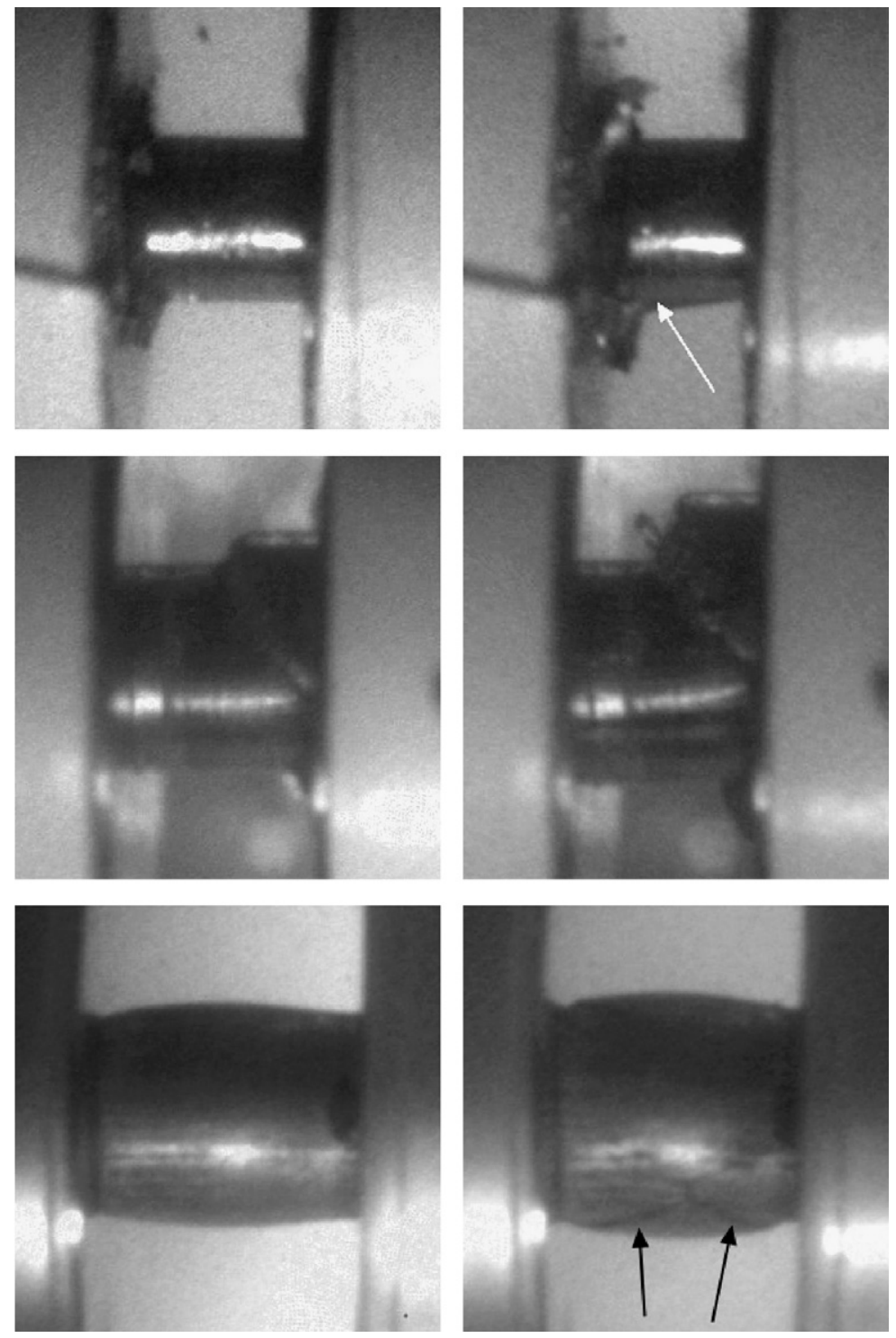

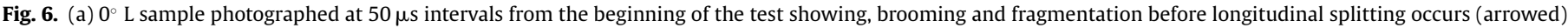

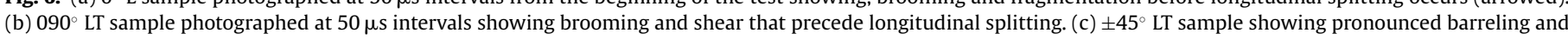
plastic deformation that precede eventual appearance of shear cracks (arrowed). 
(a)

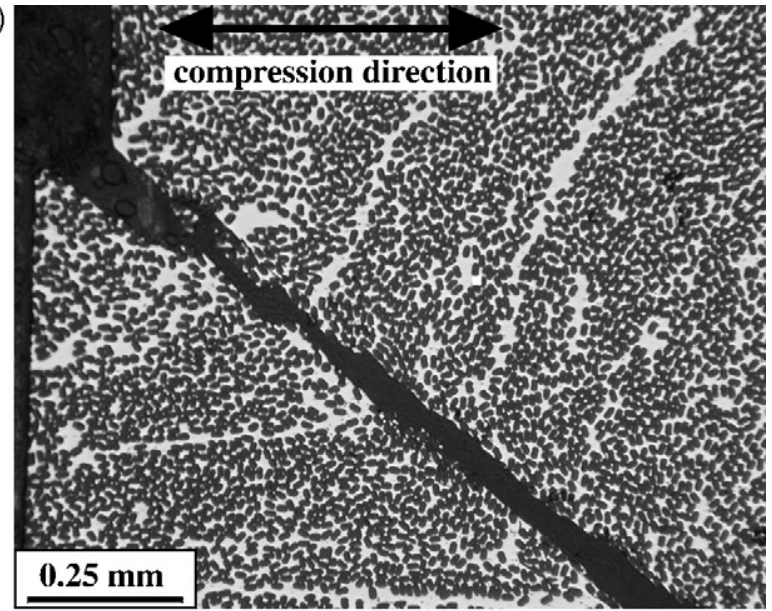

(b)

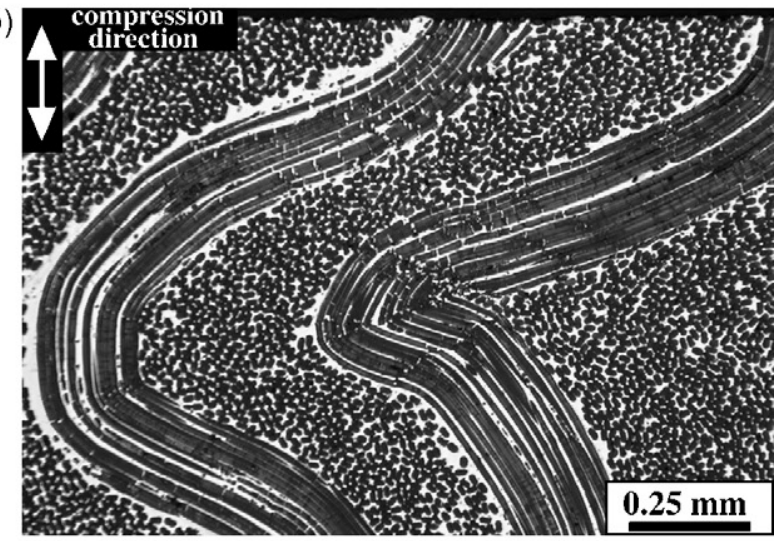

(c)

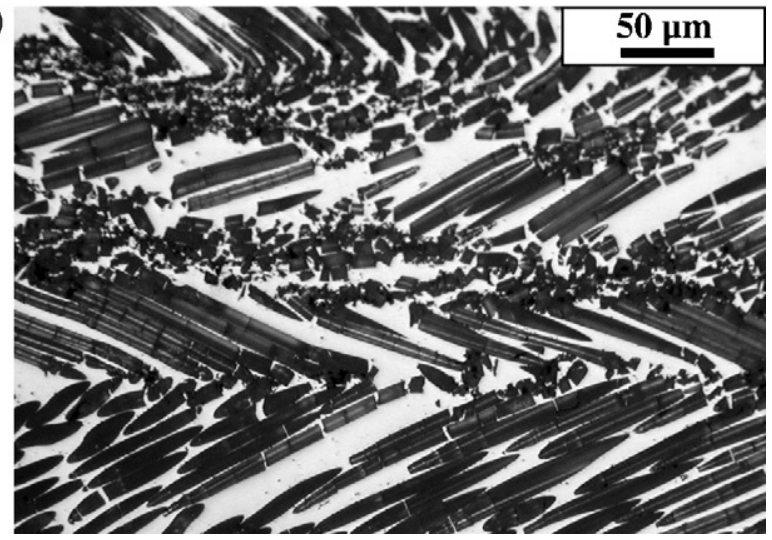

Fig. 7. (a) Section through a $0^{\circ}$ LT quasi-static sample in which the individual precursor layers of fibers may still be clearly seen even though all were initially parallel. Note the approximately $45^{\circ}$ rotation of the layers across the crack as a result of plastic deformation. (b) Micrograph of a region near the base of a $0 / 90^{\circ} \mathrm{L}$ quasi-static sample showing the intense kinking within the longitudinal fiber layers. (c) Section close to the base of a tested $0^{\circ} \mathrm{L}$ specimen tested at high strain rate showing intense fiber fragmentation accompanying kink band formation.

\subsection{Fractography}

Fig. 8 shows the surface of a broken fiber and illustrates the extent to which the alloy matrix adheres strongly to the fibers. During failure of this sample, the matrix underwent tensile separation in one region, indicated by ductile dimples to the left on the fiber surface, as well as shear failure as seen on the right of the surface.

In general, there were no significant differences between the fracture modes in quasi-static and high strain rate testing. $0^{\circ}$ samples all showed essentially similar features reflecting the principal modes of failure, i.e. shear in LT and ST specimens and longitudinal

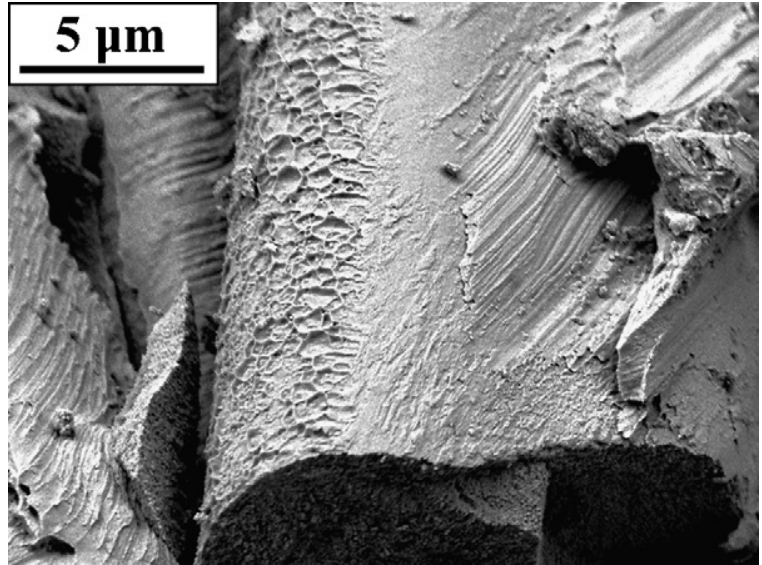

Fig. 8. Close-up of an individual "peanut-shaped" fiber showing the extremely effective bonding between the Al-6061 matrix and the Nextel 610 fibers. Note tensile dimples in matrix alloy adhering to fiber at left and shear failure of matrix at right.

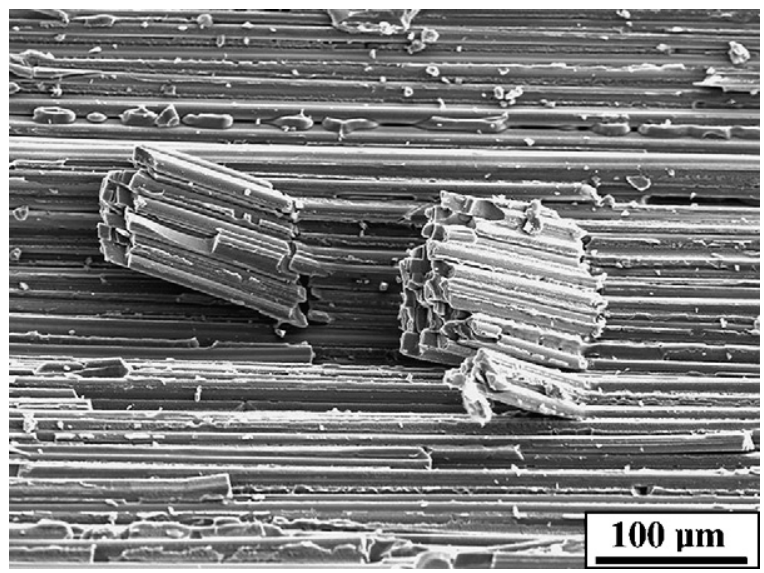

Fig. 9. $0^{\circ} \mathrm{L}$ sample showing longitudinal splitting and occasional pull-out of short lengths of fiber bundles.

splitting in L specimens. On surfaces where longitudinal splitting predominated, occasional areas showed regions where fragments of fiber bundles had been pulled out due to the excellent transverse bonding strength of the matrix, Fig. 9.

The transverse strength was in evidence again in many of the $0 / 90^{\circ}$ samples: Fig. 10(a) shows a view of an LT sample in which it is seen that many of the fibers have themselves undergone longitudinal splitting in addition to fracture normal to their lengths. This figure also shows several regions in the center (one of which is arrowed) where infiltration was incomplete, leading to the appearance of small "windows" though the ply boundary. Fig. 10(b) shows a region at a step between plies where fiber fracture and splitting is again visible but also where it can be seen that there is negligible fiber pull-out. Lack of fiber pull-out is a clear indication of a strong fiber/matrix bond.

Fig. 11 is a view of a $\pm 45^{\circ}$ ST sample and shows the very jagged appearance produced by a combination of fiber bundle tensile failure and ply shear.

\section{Discussion}

Several aspects of the results presented above merit considerable further discussion and, eventually, experimental/modeling effort. Considering first the experimental data, as anticipated it was generally found that equivalent lay-ups produced comparable data, e.g. $\pm 45^{\circ}$ ST and $0 / 90^{\circ}$ ST groups yielded similar data in both 

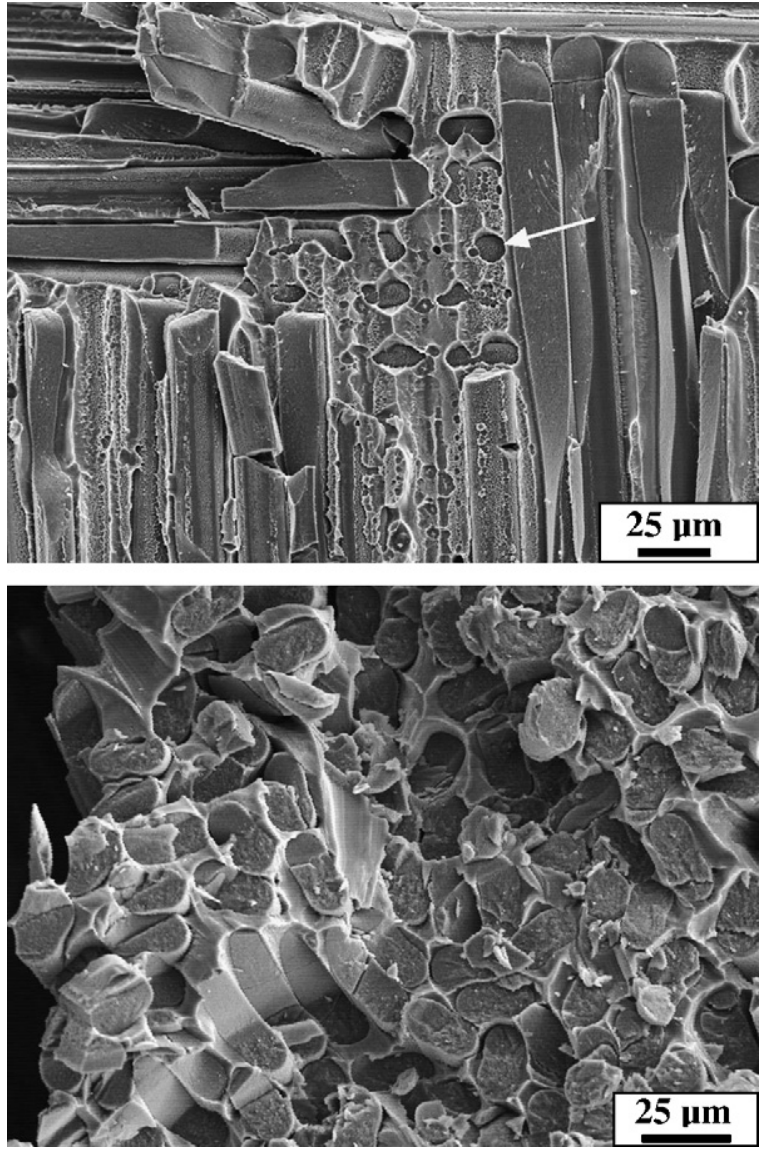

Fig. 10. (a) $0 / 90^{\circ}$ LT sample tested at high strain rate showing longitudinal fiber splitting and transverse cracking. Note also evidence of incomplete infiltration between closely packed fibers (arrowed). (b) $0 / 90^{\circ}$ LT sample tested at high strain rate showing fiber splitting and almost total absence of fiber pull-out indicative of strong fiber/matrix bonding.

quasi-static and high strain rate regimes, as $\operatorname{did} \pm 45^{\circ} \mathrm{L}$ and $\pm 45^{\circ} \mathrm{LT}$ groups.

Nevertheless, there was noticeable experimental scatter despite the extremely close attention paid to machining tolerances, sample alignment, lubrication etc. Microscopy shows that the variability between data sets may be largely accounted for by (a) local variations in fiber volume fraction from one sample to the next and (b) local variations in fiber orientation since it is well known that small

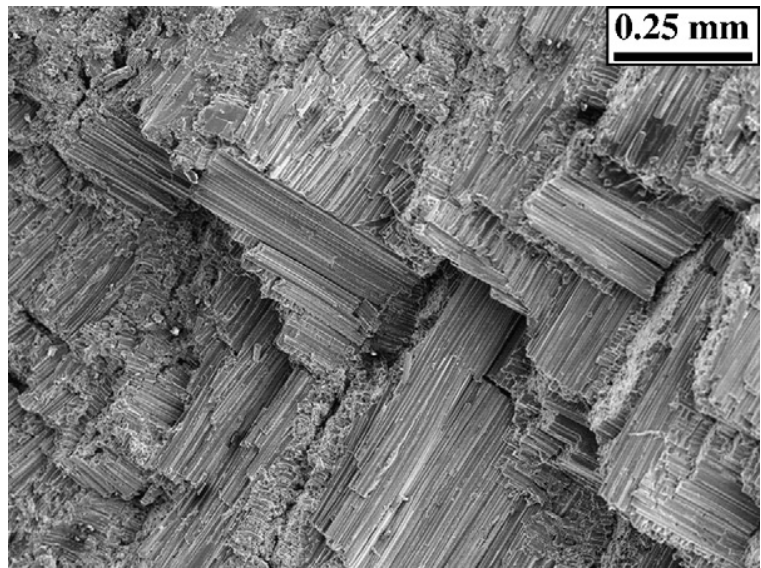

Fig. 11. $\pm 45^{\circ}$ ST sample tested at high strain rate showing jagged appearance of fracture surface resulting from alternate fiber bundle fracture and ply shear. variations in fiber orientation can profoundly affect the compressive strength $[17,18]$. Also, the initial plates were laid up from several layers of fiber 'mats' and the boundaries of the mats remained visible (see, e.g. Fig. 7(a)). Depending on the sample orientation these boundaries may provide planes of weakness where shear failure is more easily initiated.

The first really striking feature of the data, however, is that high strain rate strength data exceed the quasi-static data in all cases: the corresponding strains to failure, on the other hand, are usually substantially reduced. It is not possible to ascribe the universal increase in strength to the strain rate sensitivity of the aluminum matrix alloy since (a) it is not very marked at these strain rates and (b) in any event is weaker than in pure aluminum [19]. Strainrate dependence of the $\mathrm{Al}_{2} \mathrm{O}_{3}$ fiber strength is generally regarded as being very low as reported by Cady and Gray [3]. It may be noted parenthetically that Staehler et al. reported very strong rate sensitivity for a pure form of pure hot pressed alumina [20], however, that is not believed to be the case here.

Strain rate sensitivity in metals and alloys is conventionally measured either at the yield point or at the flow stress at a certain strain and, since many of the MMCs in the present orientations remain elastic to failure, these conventional measures do not apply here. The most probable explanation for the substantial strength increases in dynamically tested samples, therefore, is probably related to the small strain to failure. It is believed that the strength increases noted in the present work at high strain rates occur simply because inertial effects limit the motion of fractured fragments. The result is that they remain in place long enough to continue to be loaded, or to be re-loaded, for a significant period after they would have fallen away in a quasi-static test. Evidence for this comes from high-speed photography where, for example, longitudinal splitting of $0^{\circ}$ samples was seen to be well underway before the point of maximum load was reached. In a quasi-static test, these fragments would fall away before being re-loaded.

The second salient feature of the data is the observation that the strength of $0 / 90^{\circ} \mathrm{L}$ (or LT) samples was in all cases superior to that of $0^{\circ} \mathrm{L}$ samples even though only half of the $V_{f}$ of fibers was in the optimum orientation. For example, in quasi-static tests, $0^{\circ}$ samples exhibited $\sigma_{\max }$ of $1603 \mathrm{MPa}$ while $0 / 90^{\circ}$ samples yielded $\sigma_{\max }$ of $1919 \mathrm{MPa}$ with an almost identical strain to failure. Similar behavior was noted in the high strain rate samples. This result is in direct contradiction to predictions from the simple rule of mixtures and, hence, requires further consideration.

Applying the rule of mixtures to compression samples is problematical since the compressive strength and modulus of fibers are not generally available. It is often assumed that the fiber tensile properties are the same as the compressive properties, and the modulus and strength values of the fibers could therefore be taken as $380 \mathrm{GPa}$ and $3100 \mathrm{MPa}$, respectively. Taking typical yield strength and modulus values for Al6061-T6 to be 276 MPa and 68.9 GPA, respectively, and for $60 \mathrm{~V}_{\mathrm{f}} \%$ fibers, the yield strength of a $0^{\circ}$ unidirectional composite should be approximately $1900 \mathrm{MPa}$. However, it has been found that the matrix composition has a profound influence on the compressive properties of these composites and compressive strengths of $\sim 1700 \mathrm{MPa}, \sim 3600 \mathrm{MPa}$ and $\sim 4100 \mathrm{MPa}$ have been reported for composites with pure $\mathrm{Al}, \mathrm{Al}-2 \% \mathrm{Cu}$ and Al-6061 matrices respectively [10]. Analogous observations were reported above concerning Young's modulus of some of the small cylindrical samples where, again, experimentally measured values greatly exceeded those anticipated from the rule of mixtures.

Clearly, the mechanical properties are strongly influenced by the matrix composition which, in turn, strongly influences the transverse strength of the composite. It is generally accepted that, for tensile properties of unidirectionally reinforced MMCs, a strong fiber/matrix bond is undesirable since it prevents the early debonding and crack blunting which would allow cracks to be deviated. 
However, the deformation and fracture processes in compression are substantially different from those in tension where fiber failure occurs. In compression, the principal failure modes are buckling of fibers, either individually or in a coordinated fashion via kinking and brooming, and longitudinal splitting. It is reasonable that the longer these failure modes can be delayed, the higher the measured strength of the composite will be. In this context, the transverse plies present in $0 / 90^{\circ}$ samples can now be seen to be effective in constraining deformation in the transverse dimension and, hence, reducing the likelihood of early fiber buckling. Furthermore, the relatively high shear strength of the matrix also contributes to this effect.

A direct consequence of the differing deformation modes in tension and compression is that (a) significantly higher strengths are evidently available in the latter and (b) rule of mixtures values based on tensile properties are potentially very inaccurate. For example, the maximum compressive stresses measured in the present program were $3043 \mathrm{MPa}$ and $2027 \mathrm{MPa}$ for 0/90 $\mathrm{L}$ high strain rate and quasi-statically tested samples, respectively: these correspond to $98 \%$ and $61 \%$ of the predicted values for $0^{\circ}$ unidirectionally reinforced composites based upon tensile properties.

It is, therefore, apparent that MMCs of this type have great promise for applications where compression is the principal loading mode and a matrix with high interfacial shear strength is an advantage rather than a disadvantage as it is in tension. Additionally, as noted at the outset, the present tests did not specifically address the problems of producing pure compressive failure but, if the failure modes of brooming, buckling and kinking can be further delayed by detailed attention to fiber placement and lay-up, the properties will be enhanced even further.

\section{Conclusions}

Quasi-static and high strain rate testing has been carried out on several orientations of cross-ply MMCs. The measured strengths at high strain rate were found to be significantly higher than at low strain rate and it is proposed that this is due to the inertia of the fragments allowing them to be re-loaded rather than due to inherent strain rate sensitivity of the material. The strength of $0 / 90^{\circ} \mathrm{MMCs}$ was found to be greater than that of $0^{\circ} \mathrm{MMCs}$, pointing to the importance of the matrix in preventing ply splitting. It appears that the compressive modulus of the fibers may be considerably larger than their tensile modulus. The mechanical properties of small sections are strongly dependent on fiber distribution and alignment.

\section{Acknowledgements}

The authors gratefully acknowledge financial assistance during the initial phase of this research from the Army Research Office, Solid Mechanics Branch, Dr. B. LaMattina Program Manager, and NSF Award \#0242772, Office of International Science and Engineering Dr. O. Shinaishin, Program Manager.

\section{References}

[1] J.C. Huang, Y.S. Lo, G.T. Gray, Materials Chemistry and Physics 35 (1) (1993) 71-85.

[2] C.C. Poteet, I.W. Hall, Materials Science and Engineering A: Structural Materials Properties Microstructure and Processing 222 (1) (1997) 35-44.

[3] C.M. Cady, G.T. Gray, Materials Science and Engineering A: Structural Materials Properties Microstructure and Processing 298 (1-2)(2001) 56-62.

[4] M. Guden, et al., Materials Science and Engineering A: Structural Materials Properties Microstructure and Processing 425 (1-2) (2006) 145-155.

[5] M. Guden, I.W. Hall, Computers \& Structures 76 (1-3) (2000) 139-144.

[6] U. Ramamurty, T. Seshacharyulu, Materials Science and Engineering A: Structural Materials Properties Microstructure and Processing 268 (1-2) (1999) 97-103.

[7] B. Moser, et al., Composites Part A: Applied Science and Manufacturing 32 (8) (2001) 1067-1075.

[8] B. Moser, et al., Acta Materialia 52 (3) (2004) 573-581.

[9] D.M. Wilson, Journal of Materials Science 32 (10) (1997) 2535-2542.

[10] H.E. Deve, Acta Materialia 45 (12) (1997) 5041-5046.

[11] C. McCullough, H.E. Deve, T.E. Channel, Materials Science and Engineering A: Structural Materials Properties Microstructure and Processing 189 (1-2)(1994) 147-154.

[12] W.S. Lee, W.C. Sue, C.F. Lin, Composites Science and Technology 60 (10) (2000) 1975-1983.

[13] B. Roebuck, J.D. Lord, L.P. Orkney, Second European Conference on Composites Testing and Standardisation, Woodhead Publishing, Ltd, Hamburg, Germany, 1994.

[14] O. Anthoine, J.C. Grandidier, L. Daridon, Composites Science and Technology 58 (5) (1998) 735-740.

[15] J.S. Welsh, D.F. Adams, Sampe Journal 33 (1) (1997) 35-43.

[16] D.F. Adams, J.S. Welsh, Journal of Composites Technology \& Research 19 (3) (1997) 123-133.

[17] B. Budiansky, N.A. Fleck, Journal of the Mechanics and Physics of Solids 41 (1) (1993) 183-211.

[18] S.W. Yurgartis, Composites Science and Technology 30 (4) (1987) 279-293.

[19] L.D. Oosterkamp, A. Ivankovic, G. Venizelos, Materials Science and Engineering A: Structural Materials Properties Microstructure and Processing $278(1-2)$ (2000) 225-235.

[20] J.M. Staehler, et al., Materials Science and Engineering A: Structural Materials Properties Microstructure and Processing 291 (1-2) (2000) 37-45. 